Check for updates

Cite this: RSC Adv., 2019, 9, 36358

Received 28th August 2019

Accepted 31st October 2019

DOI: $10.1039 / \mathrm{c} 9 \mathrm{ra0} 6840 \mathrm{f}$

rsc.li/rsc-advances

\section{Development of a selective and sensitive colour reagent for gold and silver ions and its application to desktop scanner analysis $\uparrow$}

\begin{abstract}
Ashraf A. Mohamed, (DD * Eslam H. A. Mahmoud and Mostafa M. H. Khalil (iD
Desktop scanners can be favorable alternatives to sophisticated spectrophotometers for the assessment of analytes in complex real samples. Distinctively, our method has been thoroughly investigated, optimized, validated and successfully applied to the assessment of silver and gold in complex real samples, applying syringal rhodanine (SR) as a novel specifically tailored chromogenic reagent and using a desktop scanner as a versatile sensor. Maximum colour absorbance was obtained in the presence of cetylpyridinium chloride (CPC) and cetyltrimethylammonium chloride (CTAC) for silver and gold chelates, respectively. For each metal ion, two ternary complexes were formed depending on the SR concentration with stoichiometries of $1: 1: 1$ and $1: 2: 3$ (Ag-SR-CPC) and $1: 2: 3$ and $1: 3: 4$ (Au-SR-CTAC), respectively. The methods adhered to Beer's law for $0.15-2.5$ and $0.15-2.25 \mu \mathrm{g} \mathrm{mL}^{-1}$ with detection limits of 0.0089 and $0.0163 \mu \mathrm{g} \mathrm{mL}^{-1}$ for silver and gold, respectively. The molar absorptivities were 3.63 $\times 10^{4}$ and $6.15 \times 10^{4} \mathrm{~L} \mathrm{~mol}^{-1} \mathrm{~cm}^{-1}$ at $550 \mathrm{~nm}$ and $554 \mathrm{~nm}$, with Sandell's sensitivity indexes of 0.0029 and $0.0032 \mu \mathrm{g} \mathrm{cm}^{-2}$, respectively. The method was successfully applied to the assessment of silver and gold in a wide range of complex environmental samples.
\end{abstract}

\section{Introduction}

Spectrophotometry is a popular and commonly used technique for quantitative chemical analysis for gold and silver. However, UV/vis spectrophotometers are frequently unavailable, especially in locally deprived communities and/or under resourcelimited settings.

Sophisticated analytical techniques including inductively coupled plasma-mass spectrometry (ICP-MS), ${ }^{\mathbf{1 - 4}}$ inductively coupled plasma optical emission spectrometry (ICP-OES), ${ }^{5,6}$ neutron activation analysis (NAA), ${ }^{3,7,8}$ X-ray fluorescence (XRF), ${ }^{9}$ and atomic absorption spectrometry (AAS) $)^{\mathbf{1 0 - 1 4}}$ enable sensitive and selective determination of trace amounts of Ag(I) and Au(III) in a wide range of matrices. However, conventional spectrophotometry stands out as a relatively low cost, simple and easyto-use technique. The spectrophotometric determination of silver is usually achieved using its reaction with dithizone, ${ }^{15} 4$ (2-quinolylazo)phenol ( $p$-QAP), ${ }^{16} \quad 4,4^{\prime}$-bis(dimethylamino)thiobenzophenone, ${ }^{17}$ 2-cyano-3-iminodithiobutyrate (CIDT), ${ }^{18}$ or $2^{\prime}, 3^{\prime}$-dihydroxypyridyl-4'-azobenzene-4-arsonate (DHP-4A); ${ }^{19}$ however, that of gold is achieved using dithizone, ${ }^{20} 4$-(2-pyridylazo)resorcinol (PAR), ${ }^{21}$ 4-(2-thiazolylazo)resorcinol (TAR), ${ }^{22}$

Department of Chemistry, Faculty of Science, Ain Shams University, Abbassia, Cairo-11566, Egypt. E-mail: aamohamd@sci.asu.edu.eg; Fax: +20 224831836; Tel: +201001578849

$\uparrow$ Electronic supplementary information (ESI) available: Additional figures and tables. See DOI: 10.1039/c9ra06840f methiomeprazine hydrochloride $(\mathrm{MMH}),{ }^{23}$ 4-(2-quinolylazo) phenol ( $p$-QAP),$^{24}$ or dithiodiantipyrylmethane. ${ }^{25}$ Nevertheless, the poor selectivity, sensitivity and/or precision restrains the use of most of these reagents. But, rhodanine derivatives surpassed many of these reagents and therefore, have found vast applications in the determination of silver ${ }^{26-29}$ and gold. ${ }^{26,29-32}$ However, some difficulties were noted with the use of many rhodanine derivatives, including the relatively poor solubility of reagents and their chelates and/or the poor stability of the developed colours. Thus, surfactants were used to solubilize and stabilize the pseudo-solutions containing the ligands and/ or their metal-chelates; thereby enhancing both the selectivity and sensitivity of these methods. ${ }^{33,34}$

On the other hand, methods of digital image-based analysis (DIBA) can be simple, easy-to-use and low-cost alternatives. ${ }^{35,36}$ In DIBA, the analyte is allowed to react with a chromogenic reagent to give a coloured product whose digital images are captured and analysed to give the red, green and blue intensity values $\left(I_{\mathrm{R}}, I_{\mathrm{G}}\right.$, and $\left.I_{\mathrm{B}}\right)$. The RGB intensities, ${ }^{37-44}$ and the RGB absorbances $\left(A_{\mathrm{R}}, A_{\mathrm{G}}, A_{\mathrm{B}}\right)^{45,46}$ or thereof ${ }^{35,36}$ have been used as analytical signals in DIBA.

Herein, syringal-rhodanine (SR) was synthesized, characterized and applied as a novel and specifically tailored chromogenic reagent for the sensitive and highly selective assessment of silver(I) and gold(III) based on monitoring with a desktop scanner as a versatile low-cost sensor due to its relatively fixed light source intensity and the lack of outdoor light interference. Further, the reaction variables affecting the spectral characteristics of Ag-SR 
and $\mathrm{Au}-\mathrm{SR}$ chelates were thoroughly investigated, optimized and incorporated into respective recommended procedures for the assessment of $\operatorname{Ag}(\mathrm{I})$ and $\mathrm{Au}(\mathrm{III})$ in antiseptic and burn cream, electroplating wastewaters, and rock samples.

\section{Experimental}

\subsection{Apparatus and software}

Spectrophotometric measurements were carried out in $10 \mathrm{~mm}$ matched glass cells in the range of 200-1100 nm using a Shimadzu (Kyoto, Japan) $1650 \mathrm{UV}$-vis spectrophotometer that is controlled by a UV-probe 2.5 software. Eppendorf $20-200 \mu \mathrm{L}$ and 100-1000 $\mu \mathrm{L}$ vary-pipettes (Westbury, NY, USA) and a calibrated EDT pH-mV meter (Dover Kent, UK) were used.

A flat bottom 96-micro-well plate was used for colour absorbance measurements using an Hp-Deskjet F4200 all in one printer-scanner-copier. A conventional HP X7H29EA\#ABV Notebook running under Windows 10 Home 64 bit was used for data treatment and analysis. Photoshop CS6 was used for digital image processing and ImageJ2x software 2.1.4.7 was used for RGB channel intensities calculations. Then, for each image, the RGB colour absorbance $\left(A_{\mathrm{R}}, A_{\mathrm{G}}, A_{\mathrm{B}}\right)$ was calculated. ${ }^{35,36}$

\subsection{Materials and chemicals}

All reagents were of ACS grade and were used as received from Merck (Darmstadt, Germany) or Sigma-Aldrich (St. Louis, MO, USA). Unless otherwise stated, deionized water and aqueous solutions were used throughout.

Syringal-rhodanine (SR) was synthesized according to Julian and Sturgis ${ }^{\mathbf{4 7}}$ by adding $3.0 \mathrm{~g}$ of freshly prepared, fused and powdered sodium acetate to $30 \mathrm{~mL}$ glacial acetic acid containing 0.03 mol rhodanine and $0.03 \mathrm{~mol}$ 4-hydroxy-3,5-dimethoxy benzaldehyde (syringaldehyde). The mixture was refluxed for 4 hours with occasional shaking. The solid crude SR was poured into a $1 \mathrm{~L}$ beaker containing iced water, triturated vigorously and then filtered. To the filtrate, $\mathrm{Na}_{2} \mathrm{CO}_{3}$ was added stepwise until no effervescence was observed. The resulting second crop of crude SR was collected and added to the first crop. The melting point of crude SR was $244-248^{\circ}$. Double recrystallization from glacial acetic acid yielded orange-yellow fine crystals of pure SR with mp $255-256^{\circ}$ which is in excellent agreement with the previously reported data. ${ }^{48}$ The purity of the reagent was confirmed by thin-layer chromatography with benzenepetroleum ether $(1: 4 \mathrm{v} / \mathrm{v})$ as eluent. A single yellow band was obtained for the pure product.

An ethanolic stock solution of $5.0 \mathrm{mmol} \mathrm{L}^{-1} \mathrm{SR}$ was prepared by dissolving the appropriate amount of SR in absolute ethanol. This solution was stable for more than 2 months. A $1.0 \mathrm{mmol}$ $\mathrm{L}^{-1}$ SR working solution was prepared daily by appropriate dilution of the stock solution with absolute ethanol.

A stock standard $0.01 \mathrm{~mol} \mathrm{~L}^{-1} \mathrm{Ag}$ (I) solution was prepared by dissolving the suitable amount of dried silver nitrate in $0.02 \mathrm{~mol} \mathrm{~L}^{-1}$ nitric acid. More dilute working silver(I) solutions were prepared daily by appropriate dilution of its stock solution.

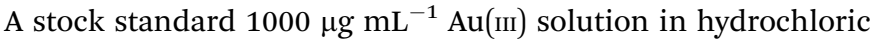
acid, was purchased from Sigma-Aldrich (St. Louis, MO, USA).
More dilute working gold(III) solutions were prepared by appropriate dilution of its stock solution.

A composite surfactant-buffer solution that is $4.0 \mathrm{mmol} \mathrm{L}^{-1}$ cetylpyridinium chloride (CPC) and $50.0 \mathrm{mmol} \mathrm{L}^{-1}$ borate buffer of $\mathrm{pH} 9.80$ was prepared by dissolving the appropriate amounts of CPC and borax in water and adjusting the $\mathrm{pH}$ to $9.80 \pm 0.05$.

Cetyltrimethylammonium chloride (CTAC) was prepared as a $20.0 \mathrm{mmol} \mathrm{L}^{-1}$ solution by dissolving the appropriate amount in deionized water.

A borate buffer series of $\mathrm{pH}$ 7.8-10.8 was prepared by adjusting the $\mathrm{pH}$ of $50.0 \mathrm{mmol} \mathrm{L}^{-1}$ sodium tetraborate solution with hydrochloric acid or sodium hydroxide solution using a pre-calibrated $\mathrm{pH}$ meter.

\subsection{Treatment of burn cream for silver determination}

A silver-sulfadiazine burn cream was purchased from the local market. About $0.30 \mathrm{~g}$ of the cream was exactly weighed and dissolved in $10 \mathrm{~mL}$ of $0.10 \mathrm{~mol} \mathrm{~L}^{-1}$ nitric acid. The solution was filtered to remove any insoluble matter. The filtrate was quantitatively transferred to a $100 \mathrm{~mL}$ volumetric flask, the residue was washed with deionized water, the washing was added to the flask and the volume was diluted to the mark with deionized water. This solution was directly analysed following the recommended procedure.

\subsection{Treatment of wastewater samples for gold determination}

Electroplating wastewater was collected from Asfour company, Cairo. The $\mathrm{pH}$ was adjusted to $2.0 \pm 0.1$ using dilute $\mathrm{HNO}_{3}$ and then filtered using a $0.45 \mu \mathrm{m}$ membrane filer. A $100 \mathrm{~mL}$ of this solution was preconcentrated by evaporation to $1 / 10$ its volume, cooled, diluted to the mark in a $10 \mathrm{~mL}$ volumetric flask and analyzed following the recommended procedure.

\subsection{Treatment of rock samples for silver and gold determination}

Rock samples were ground in an automatic mortar grinder, sieved through a $2 \mathrm{~mm}$ stainless steel sieve to exclude gruff materials. A $1.00 \mathrm{~g}$ of the finely powdered sample was dissolved in a Teflon beaker in an $\mathrm{HF} / \mathrm{HNO}_{3} / \mathrm{H}_{2} \mathrm{SO}_{4}$ mixture ${ }^{49}$ and analysed following the respective recommended procedure.

\subsection{Recommended procedure for silver and gold assessment}

An aliquot of the sample solution or the working silver(I) standard solution containing not more than $25 \mu \mathrm{g}$ Ag was transferred to a $10 \mathrm{~mL}$ volumetric flask. A $5.0 \mathrm{~mL}$ of the composite CPC-borate solution and $500 \mu \mathrm{L}$ of the working SR solution were added. The reacting solution was diluted to the mark with water, mixed well, left at room temperature for $10 \mathrm{~min}$ for complete colour development, and the absorbance was measured at $550 \mathrm{~nm}$ against a similarly prepared reagent blank. However, for gold determination: an aliquot of the sample solution or the working gold(III) standard solution containing not more than $22.5 \mu \mathrm{g}$ Au was transferred into a $10 \mathrm{~mL}$ 
volumetric flask. A $1000 \mu \mathrm{L}$ the working CTAC solution and 500 $\mu \mathrm{L}$ of the working SR solution were added. The reacting solution was diluted to the mark with borate buffer, mixed well, left at room temperature for $10 \mathrm{~min}$ for complete colour development, and the absorbance was measured at $554 \mathrm{~nm}$ against a similarly prepared reagent blank.

From each flask, a $300 \mu \mathrm{L}$ aliquot was pipetted into the micro-well plate and an image was scanned using the desktop scanner. As previously reported, ${ }^{35,36}$ various scan resolutions of 300,600 and 1200 dpi gave essentially the same response; therefore, a scan resolution of 300 dpi was adopted for simplicity. From each image, a representative homogenous circular area (60 pixels in diameter) was cropped using Photoshop CS6, and the RGB colour intensities $\left(I_{\mathrm{R}}, I_{\mathrm{G}}, I_{\mathrm{B}}\right)$ were registered by ImageJ $2 x$ and then the colour absorbance for each channel $\left(A_{\mathrm{R}}, A_{\mathrm{G}}, A_{\mathrm{B}}\right)$ was calculated from $\left[A_{\mathrm{RGB}}=\log \left(I_{\mathrm{o}} / I\right)\right]$; where $I_{\mathrm{o}}$ and $I$ are the channel intensity of the blank and sample, respectively. ${ }^{35,36}$ The silver or gold concentration was determined from a similarly prepared calibration graph obtained with a series of standard solutions.

\section{Results and discussion}

\subsection{Dissociation constants of SR}

Protonated syringal-rhodanine (SR) has the general formula $\mathrm{H}_{3} \mathrm{~L}^{+}$.

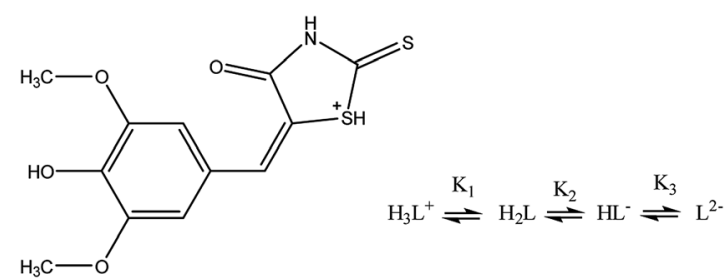

Therefore, four species are involved in the SR acid dissociation process, according to the above equation. The respective dissociation constants were determined spectrophotometrically in $1: 1$ ethanol-water. Where, $K_{1}, K_{2}, K_{3}$ were assigned to the deprotonation of $\mathrm{SH}^{+}, \mathrm{NH}$, and $\mathrm{OH}$ groups, respectively. The deprotonation constant $K_{1}$, couldn't be determined due to the instability of the reagent in strongly acidic $\mathrm{HCl}$ media $(\mathrm{pH}<3.0)$. However, $K_{2}$ and $K_{3}$ were determined by spectral measurements of $0.03 \mathrm{mmol} \mathrm{L}^{-1} \mathrm{SR}$ solutions adjusted to various $\mathrm{pH}$ values between 3.0-13.0, Fig. 1A. The obtained spectral data were treated with Datan software, ${ }^{50}$ Fig. 1B. The molar ratios distribution of various dissociable species showed intersections corresponding to the dissociation constants $K_{2}$ and $K_{3}$ with values of 6.61 and 10.87 , respectively. However, the dissociation constants can be also derived graphically or mathematically from the conventional $A-\mathrm{pH}$ relation at the respective wavelength maxima.

Absorption spectra of Ag-SR-CPC and Au-SR-CTAC chelates. The absorption spectra of the ternary SR-CPC and $\mathrm{Au}-$ SR-CTAC chelates measured versus their reagent blank are shown in Fig. S1. $\dagger$ The ternary chelates exhibited absorption maxima at 550 and $554 \mathrm{~nm}$, respectively. Their reagent blank versus water exhibited maximum absorbance at $488 \mathrm{~nm}$. The colours of the ternary $\mathrm{Ag}-\mathrm{SR}-\mathrm{CPC}$ and $\mathrm{Au}-\mathrm{SR}-\mathrm{CTAC}$ complexes were
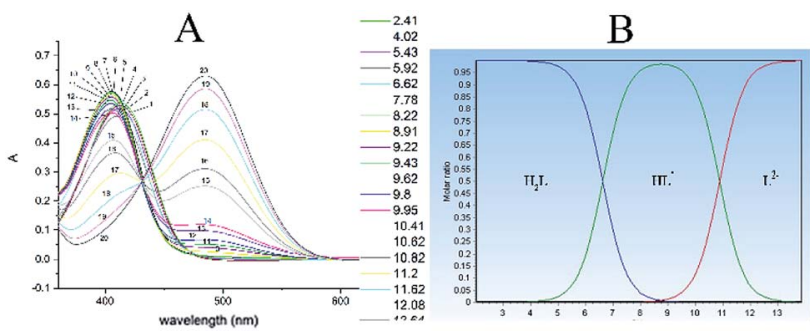

Fig. 1 (A) Effect of $\mathrm{pH}$ on the spectral characteristics of $3 \times 10^{-5} \mathrm{~mol} \mathrm{~L}^{-1}$ SR. Curves: $1, \mathrm{pH}=2.41 ; 2, \mathrm{pH}=4.02 ; 3, \mathrm{pH}=5.43 ; 4, \mathrm{pH}=5.92 ; 5, \mathrm{pH}$ $=6.62 ; 6, \mathrm{pH}=7.78 ; 7, \mathrm{pH}=8.22 ; 8, \mathrm{pH}=8.91 ; 9, \mathrm{pH}=9.22 ; 10, \mathrm{pH}=$ 9.43; $11, \mathrm{pH}=9.62 ; 12, \mathrm{pH}=9.80 ; 13, \mathrm{pH}=9.95 ; 14, \mathrm{pH}=10.41 ; 15, \mathrm{pH}$ $=10.62 ; 16, \mathrm{pH}=10.82 ; 17, \mathrm{pH}=11.20 ; 18, \mathrm{pH}=11.62 ; 19, \mathrm{pH}=12.08$; $20, \mathrm{pH}=12.64$. (B) Molar ratios of various species and $\mathrm{p} K_{\mathrm{a}}$ values of $\mathrm{SR}$ calculated using Datan software. $\mathrm{p} K_{1}=6.61 ; \mathrm{p} K_{2}=10.87$.

established instantaneously. Moreover, the absorbance values of the silver and gold complexes were stable for more than 45 minutes. However, a 10 min standing time was allowed before absorbance and scanning measurements to ensure full colour development.

\subsection{Effect of $\mathbf{p H}$}

Preliminary experiments showed that the Ag-SR-CPC and $\mathrm{Au}-$ SR-CTAC complexes are best formed in alkaline media. Therefore, the effect of $\mathrm{pH}$ on the absorbance of the $\mathrm{Ag}$ - and $\mathrm{Au}$ chelates were studied over the $\mathrm{pH}$ range 8.0-12.0. Maximum spectrophotometric absorbances and colour absorbances of the $\mathrm{Ag}$ - and $\mathrm{Au}$-chelates were exhibited in the $\mathrm{pH}$ ranges of 9.6-10.2 and 9.6-10.4, for the Ag- and Au-chelates, respectively, Fig. 2AC. Therefore, borate buffers of pH 9.8 and 10 were adopted in the respective recommended procedures. The green channel colour absorbances showed the same behaviour as that of the spectrophotometric absorbances. The corresponding digital images and their cropped images are given in Fig. S2A and B. $\dagger$ Over $\mathrm{pH}$ 10.4, appreciable fraction of $\mathrm{OH}^{-}$ions is present to compete with SR to form hydroxo-complexes with $\mathrm{Ag}(\mathrm{I})$ and $\mathrm{Au}(\mathrm{III})$ and therefore the absorbances decreased.

\subsection{Effect of syringal-rhodanine reagent}

The effect of syringal-rhodanine reagent concentration was investigated, at the optimum $\mathrm{pH}$, by measuring the
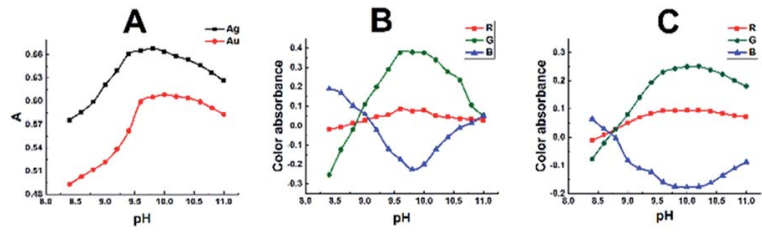

Fig. 2 Effect of $\mathrm{pH}$ on the absorbance of Ag-SR-CPC and Au-SRCTAC chelates. (A) spectrophotometric data. (B) and (C) corresponding DIBA results for the Ag-SR-CPC and Au-SR-CTAC chelates, respectively. $\left[\mathrm{Ag}^{+}\right]=\left[\mathrm{Au}^{3+}\right]=2 \mu \mathrm{g} \mathrm{mL}^{-1} ; \mathrm{CTAC}$, cetyltrimethyl ammonium chloride; $C P C$, cetyl pyridinium chloride; other conditions are those of the recommended procedure. 
spectrophotometric absorbance and digital image colour absorbance of solutions containing 1 or $2 \mu \mathrm{g} \mathrm{mL} \mathrm{m}^{-1}$ of silver or gold, following the recommended procedure and using various amounts of SR ranging between 0.01 and $0.10 \mathrm{mmol} \mathrm{L}^{-1} \mathrm{SR}$, respectively. Maximum absorbances were obtained in the presence of $0.05 \mathrm{mmol} \mathrm{L}^{-1} \mathrm{SR}$ reagent, as shown in Fig. S3A-C. $\dagger$ The corresponding scanner digital images and their cropped areas are shown in Fig. S4A-D. $\dagger$ At high SR concentrations, association of ligand occurs resulting in exponential increase of the blank absorbance with the simultaneous decrease in the net sample absorbance.

\subsection{Effect of surfactant's type and concentration}

The effects of various surfactants of the cationic, anionic and nonionic types on the spectral characteristics of the binary $\mathrm{Ag}-\mathrm{SR}$ and $\mathrm{Au}-\mathrm{SR}$ chelates were studied. Surfactants were used at concentrations above their critical micellization concentration (c.m.c.). Maximum colour absorbance of the chelates was attained with cationic surfactants, where CPC and CTAC were the optimum sensitizers for the colour reactions of silver and gold, respectively, as shown in Fig. 3A-F. The corresponding scanner images and their cropped areas are shown in Fig. S5A-D. $\dagger$

The binary Ag-SR and Au-SR chelates were solubilized in presence of $\geq 0.5 \mathrm{mmol} \mathrm{L}^{-1}$ of CPC or CTAC and using other conditions of the recommended procedure. Moreover, the maximum absorbances of the sensitized complexes were obtained at concentrations of 2.0 and $1.0 \mathrm{mmol} \mathrm{L}^{-1} \mathrm{CPC}$ and CTAC, respectively, and these were therefore adopted in the recommended procedure.

Further, the sensitization of the colour reactions was exhibited at surfactant's concentrations laying well below its own critical micellar concentration. (The c.m.c. of CPC and CTAC have been reported as 0.90 and $0.98 \mathrm{mmol} \mathrm{L}^{-1}$,
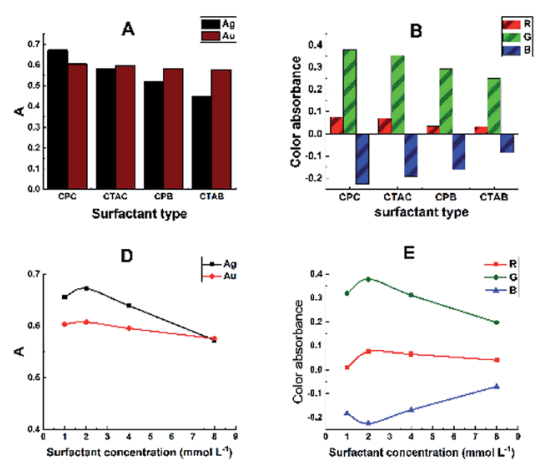

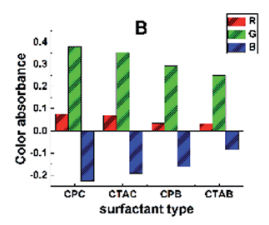

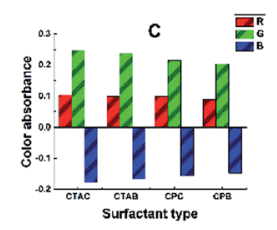

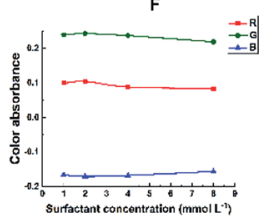

Fig. 3 Effect of some cationic surfactants on the spectral characteristics of $\mathrm{Ag}-\mathrm{SR}$ and $\mathrm{Au}-\mathrm{SR}$ chelates. CTAB, cetyltrimethyl ammonium bromide; CPB, cetyl pyridinium bromide; except for the abscissa variable, other conditions and symbols are those of Fig. 2. (A) Spectrophotometric data. (B and C) Corresponding DIBA results for the AgSR-CPC and Au-SR-CTAC chelates, respectively. (D) Spectrophotometric data for the effects of surfactant's concentration. ( $E$ and $F$ ) Corresponding DIBA results for $\mathrm{Ag}-\mathrm{SR}$ and $\mathrm{Au}-\mathrm{SR}$ chelates, respectively. respectively ${ }^{51}$ ). Consequently, the surfactant interacts with the binary chelate to form true ternary complexes.

\subsection{Effect of solvent's type and concentration}

Various miscible solvents were tested to fully solubilize the reagent and its Ag-SR-CPC and $\mathrm{Au}-\mathrm{SR}-\mathrm{CTAC}$ chelates. Preliminary experiments were conducted at a fixed final solvent concentration of $10 \%$. However, maximum enhancement of the absorbances was obtained in the presence of $5 \%$ ethyl alcohol; and therefore, was adopted in the recommended procedure. The results are shown in Fig. S6A-F. $\uparrow$ The corresponding digital images and their cropped areas are shown in Fig. S7A-D. $\dagger$

\subsection{Effect of the order of addition of reagents}

The effect of possible orders of addition of all reactants was studied to figure out the optimum order that results in maximum colour intensity of the chelates. Fig. S8A-D $\dagger$ summarizes the obtained results obtained using various orders of additions. Data revealed that the optimum order was $\operatorname{Ag}(\mathrm{I})$ followed by a composite CPC-borate solution and then the SR reagent; while for gold the order should be $\mathrm{Au}(\mathrm{III})$, followed by CTAC and borate buffer and then the SR reagent.

\subsection{Stoichiometry of the complexes}

The molar ratio and Job's continuous variation methods were utilized to determine the $\mathrm{M}: \mathrm{L}$ ratio in the complexes at the adopted optimum conditions of the recommended procedure. Experiments were performed using $1 \times 10^{-5} \mathrm{~mol} \mathrm{~L}^{-1} \mathrm{Ag}(\mathrm{I})$ or $\mathrm{Au}(\mathrm{III})$. The results showed that $\mathrm{Ag}(\mathrm{I})$ ion forms $1: 1$ and $1: 2$ complexes with absorption maxima at 560 and $550 \mathrm{~nm}$, respectively; while $\mathrm{Au}(\mathrm{III})$ forms $1: 2$ and $1: 3$ complexes with absorption maxima at 580 and $554 \mathrm{~nm}$, respectively, depending on the ligand (SR) concentration Fig. $4 \mathrm{~A}-\mathrm{H}$, the scanned and cropped images of various $\mathrm{M}: \mathrm{L}$ ratios are shown in Fig. S9. $\dagger$
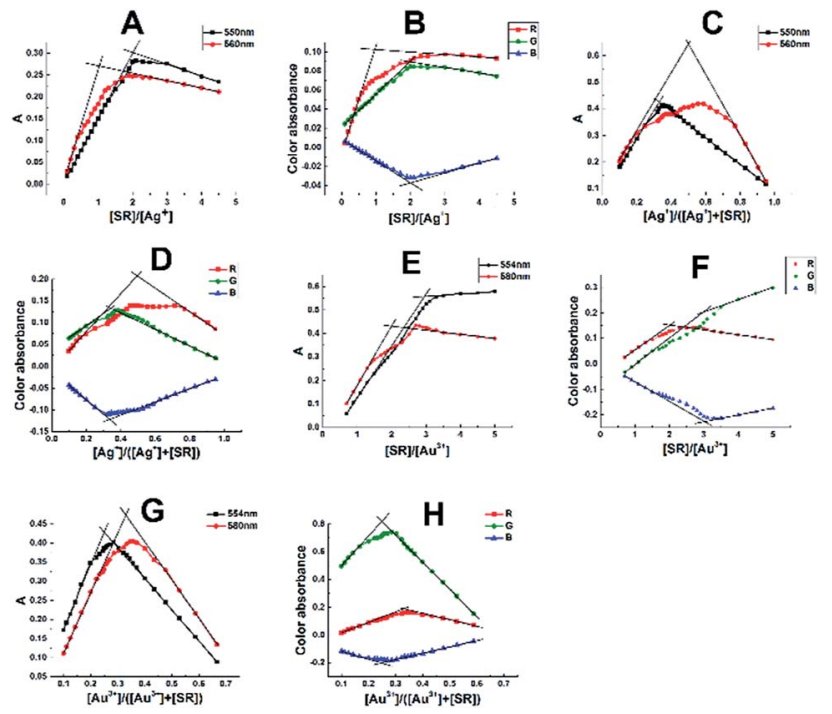

Fig. 4 Molar ratio and continuous variation plots of the Ag-SR (A-D) and $\mathrm{Au}-\mathrm{SR}(\mathrm{E}-\mathrm{H})$ ternary complexes. 


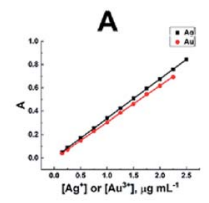

D

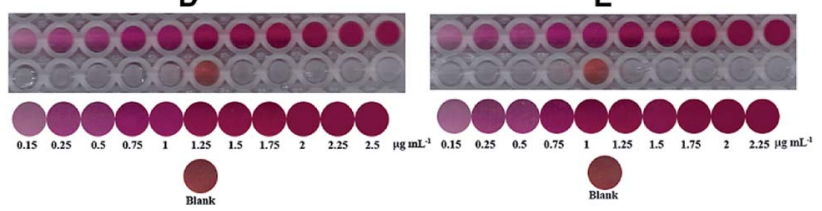

Fig. 5 Calibration plots for the determination of $A g(I)$ and $A u(I I)$; (A) spectrophotometrically; (B) and (C) DIBA-based data; (D) and (E) are scanned and cropped images of Ag-SR-CPC and Au-SR-CTAC chelates, respectively. Except for the abscissa variable, other conditions are those of Fig. 2. Captured images were arbitrarily compressed to fit into the page margins; however, for image processing, the original uncompressed images were used.

From these figures, it's clear that the green channel perfectly represents the orange-red $1: 2(\mathrm{Ag}: \mathrm{SR})$ and $1: 3$ (Au:SR) complexes; while the red channel perfectly represents the purplish-blue 1:1 (Ag:SR) and 1:2 (Au:SR) complexes, respectively.

Similarly, the surfactant ratios in the ternary complexes were determined in a similar way by molar ratio method, by increasing the CPC or CTAC concentration while maintaining a constant $\mathrm{M}: \mathrm{L}$ ratios of $1: 1 \mathrm{Ag}-\mathrm{SR}, 1: 2 \mathrm{Ag}-\mathrm{SR}, 1: 2 \mathrm{Au}-\mathrm{SR}$, or $1: 3 \mathrm{Au}-\mathrm{SR}$ complexes. The study confirmed the formation of $1: 1: 1$ and $1: 2: 3$ (Ag-SR-CPC) and $1: 2: 3,1: 3: 4$ (Au-SRCTAC) complexes, respectively.

Further, the conditional stability constants $\left(\beta_{n}^{\prime}\right)$ of the $\mathrm{M}-\mathrm{L}$ complexes were determined from the molar ratio and the continuous variation plots using the equation ${ }^{52}$

$$
\beta_{n}^{\prime}=\frac{\left[\mathrm{ML}_{n}\right]}{[\mathrm{M}][\mathrm{L}]^{n}}=\frac{\frac{A_{\mathrm{t}}}{A_{\mathrm{ex}}} C_{\mathrm{M}}}{\left[C_{\mathrm{M}}-\frac{A_{\mathrm{t}}}{A_{\mathrm{ex}}} C_{\mathrm{M}}\right]\left[C_{\mathrm{L}}-n \frac{A_{\mathrm{t}}}{A_{\mathrm{ex}}} C_{\mathrm{M}}\right]^{n}}
$$

where $A_{\mathrm{t}}$ and $A_{\mathrm{ex}}$ are the observed and extrapolated absorbances respectively, $C_{\mathrm{M}}$ and $C_{\mathrm{L}}$ are the analytical concentration of metal and ligand, $[\mathrm{M}],[\mathrm{L}]$, and $\left[\mathrm{ML}_{n}\right]$ are the equilibrium concentration of the metal, ligand and complex, respectively. Here, in case of DIBA the absorbances are substituted by the colour absorbances. The conditional stability constants of the $1: 1$, $1: 2(\mathrm{Ag}-\mathrm{SR})$ and $1: 2,1: 3(\mathrm{Au}-\mathrm{SR})$ complexes derived from the spectrophotometric and digital image-based measurements were given in Table $\mathrm{S} 1, \uparrow$ showing the excellent agreement between the spectrophotometric and scanner-based measurements. Further, the data show that, the higher $1: 2(\mathrm{Ag}-\mathrm{SR})$ and $1: 3$ (Au-SR) complexes exhibited a four-orders-of-magnitude stability compared to the lower $1: 1(\mathrm{Ag}-\mathrm{SR})$ and $1: 2(\mathrm{Au}-\mathrm{SR})$ complexes, respectively.

\subsection{Calibration and precision}

The suggested method adhered to Beer's law for 0.15-2.50 and $0.15-2.25 \mu \mathrm{g} \mathrm{mL}{ }^{-1}$ of silver and gold, at 550 and $554 \mathrm{~nm}$, respectively. The corresponding molar absorptivities, as determined by a least-squares fit for 17 results, were $3.6 \times 10^{4}$ and $6.1 \times 10^{4} \mathrm{~L} \mathrm{~mol}^{-1} \mathrm{~cm}^{-1}$, for the $\mathrm{Ag}$ - and Au-based chelates, respectively, Fig. 5A. The Sandell's sensitivities were 0.0029 and $0.0032 \mu \mathrm{g} \mathrm{cm}^{-2}$, respectively. A plot of the green colour absorbance versus silver or gold concentration exhibited excellent linearity, typical to spectrophotometric measurements, Fig. 5B, C and Table S2. $\dagger$ The detection limits were 0.0089 and $0.0163 \mu \mathrm{g} \mathrm{mL^{-1 }}$ for silver and gold, respectively. The quantification limits were 0.0296 and $0.0544 \mu \mathrm{g} \mathrm{mL}^{-1}$ for silver and gold, respectively. The spectrophotometric and digital image-based data were in excellent agreement as shown in Fig. 5A-E and Table S2, $\uparrow$ with the advantage of the low-cost, availability, and affordability of scanners compared to sophisticated spectrophotometers, showing the high efficacy of scanner image-based measurements.

\subsection{Effects of diverse ions}

The effects of foreign ions on the determination of $2 \mu \mathrm{g} \mathrm{mL}$ $\mathrm{Ag}(\mathrm{I})$ or $\mathrm{Au}(\mathrm{III})$ were thoroughly studied, following the

Table 1 Effect of foreign ions on the determination of silver(I) and gold(III) as the ternary complexes ${ }^{a}$

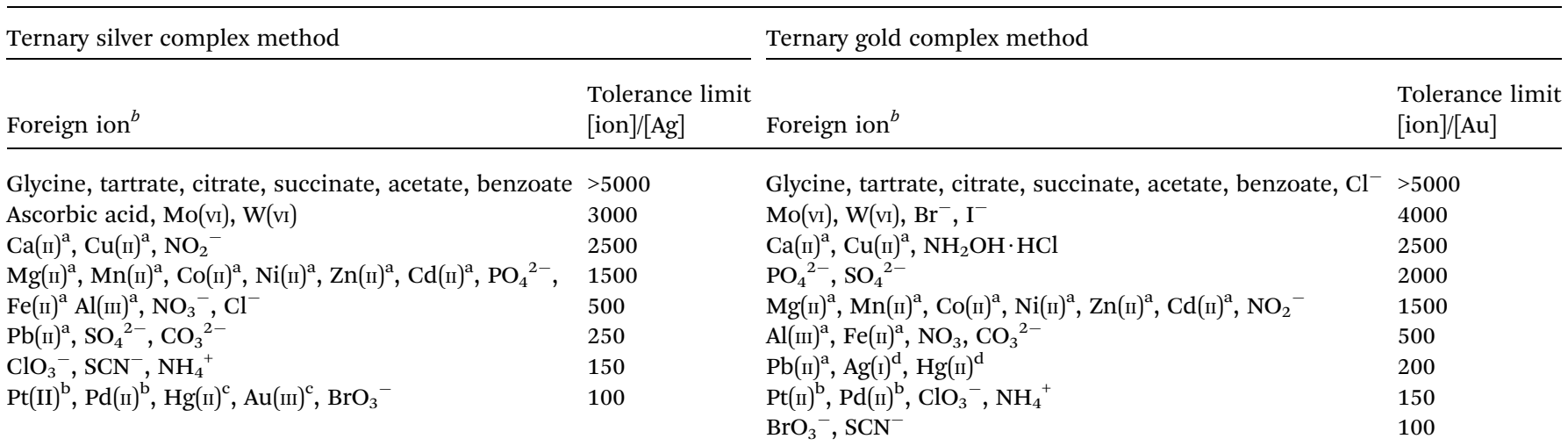

${ }^{a}$ Conditions were those of the recommended procedure using $2 \mu \mathrm{g} \mathrm{mL}{ }^{-1} \mathrm{Ag}(\mathrm{I})$ or Au(III). ${ }^{b}$ Masking agents: (a) $1 \mathrm{~mL} 0.01 \mathrm{~mol} \mathrm{~L}{ }^{-1} \mathrm{EDTA} / \mathrm{citrate}^{-}$

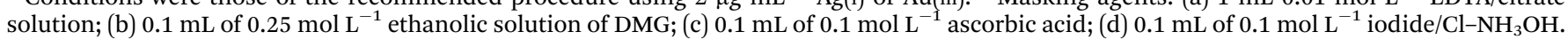


Table 2 Results of the determination of silver and gold in goldmines samples using DIBA, spectrophotometric and ICP-AES methods; $n=5$

\begin{tabular}{|c|c|c|c|c|c|c|c|c|c|}
\hline \multirow[b]{2}{*}{ Source } & \multirow{2}{*}{$\begin{array}{l}\text { ICP } \\
\text { Mean } \pm \mathrm{SD}\left(\mu \mathrm{g} \mathrm{g}^{-1}\right)\end{array}$} & \multicolumn{4}{|l|}{ Spectrophotometer } & \multicolumn{4}{|l|}{ DIBA (G) } \\
\hline & & Mean $\pm \operatorname{SD}\left(\mu \mathrm{g} \mathrm{g}^{-1}\right)$ & $F_{0.05} F_{\text {table }}=6.388$ & $\begin{array}{l}t_{0.05} t_{\text {table }}= \\
2.306\end{array}$ & $P_{0.05}$ & $\begin{array}{l}\text { Mean } \pm \\
\operatorname{SD}\left(\mu \mathrm{g} \mathrm{g}^{-1}\right)\end{array}$ & $F_{0.05} F_{\text {table }}=6.388$ & $\begin{array}{l}t_{0.05} t_{\text {table }}= \\
2.306\end{array}$ & $P_{0.05}$ \\
\hline \multicolumn{10}{|c|}{ Gold in presence of other precious metals } \\
\hline Umm urayyat & $31.66 \pm 0.36$ & $31.56 \pm 0.36$ & 1.00 & 0.43 & 0.67 & $31.57 \pm 0.36$ & 1.00 & 0.41 & 0.69 \\
\hline Haimour & $12.58 \pm 0.01$ & $12.49 \pm 0.02$ & 4.00 & 1.31 & 0.06 & $12.61 \pm 0.01$ & 1.00 & 1.18 & 0.08 \\
\hline Abu Marawat & $12.74 \pm 0.02$ & $13.03 \pm 0.03$ & 2.25 & 0.63 & 0.61 & $13.13 \pm 0.04$ & 4.00 & 0.87 & 0.57 \\
\hline Um Atoud & $20.12 \pm 0.14$ & $20.36 \pm 0.14$ & 1.00 & 1.63 & 0.11 & $20.52 \pm 0.15$ & 1.15 & 1.80 & 0.11 \\
\hline \multicolumn{10}{|c|}{ Silver in presence of other precious metals } \\
\hline Um qurayyat & $0.52 \pm 0.01$ & $0.51 \pm 0.01$ & 1.619 & 0.63 & 0.53 & $0.50 \pm 0.01$ & 1.691 & 0.66 & 0.51 \\
\hline Haimour & $3.37 \pm 0.08$ & $3.32 \pm 0.07$ & 1.433 & 0.97 & 0.21 & $3.29 \pm 0.08$ & 1.024 & 0.99 & 0.19 \\
\hline
\end{tabular}

recommended procedure. The tolerance limit was taken as the ratio of the foreign ion to the analyte that produced $\mathrm{a} \pm 5 \%$ error in the absorbance value.
Despite the extraordinary selectivity of SR towards silver and gold, few precious metal ions interfered with the determination.

Table 3 Comparison with other spectrophotometric methods for silver and gold determination

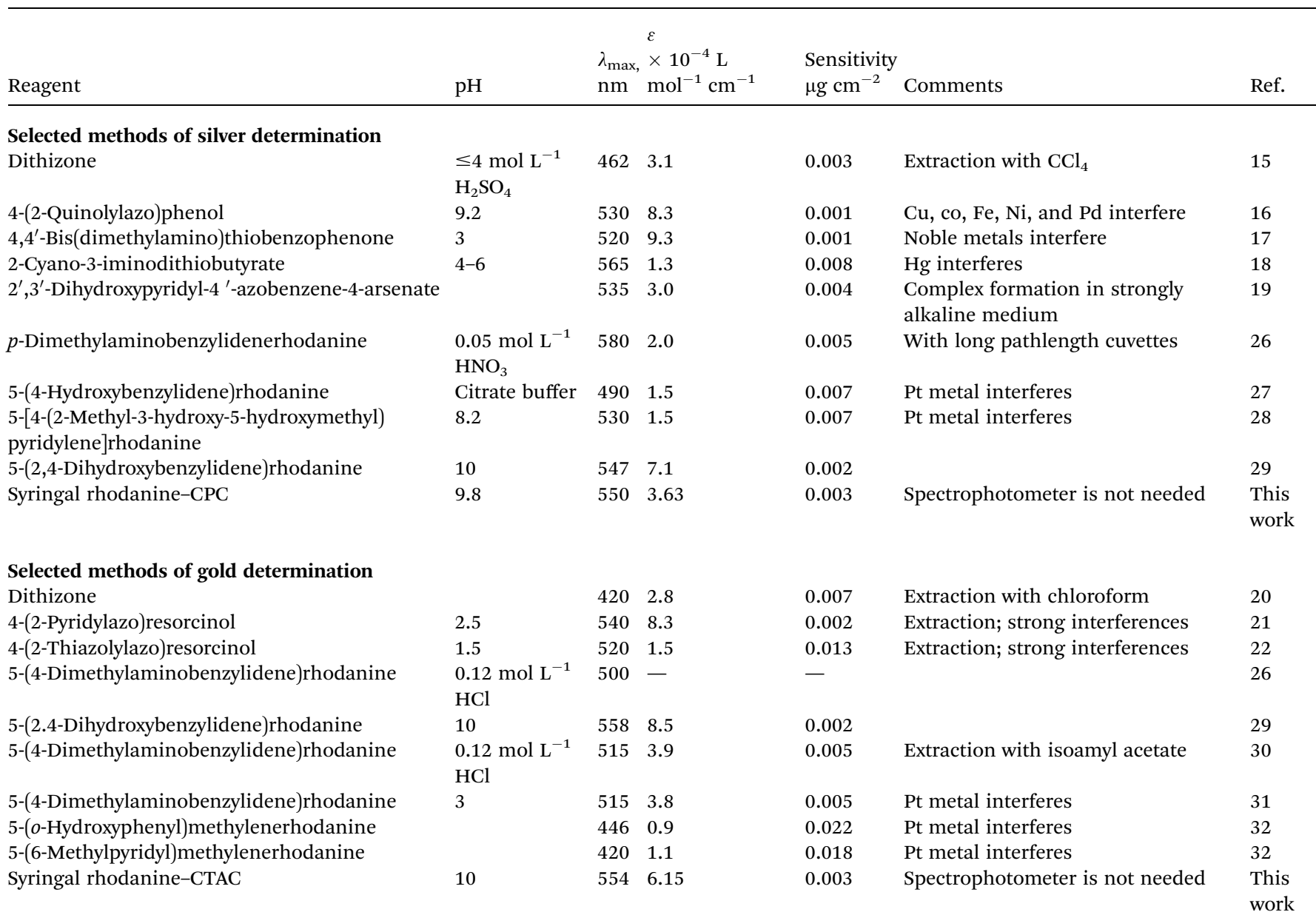


Therefore, some masking agents were adopted to impart extra selectivity to the developed methods. The results obtained are illustrated in Table 1. However, in the implemented method, an EDTA-citrate masking solution was adopted to enhance the tolerance limits of the proposed highly selective methods towards some metal ions, e.g., $\mathrm{Cu}(\mathrm{II})$ and $\mathrm{Fe}(\mathrm{II}, \mathrm{III})$. Dimethylglyoxime (DMG) was effective in masking $\mathrm{Pd}(\mathrm{II})$ and $\mathrm{Pt}(\mathrm{II})$. Ascorbic acid was used to mask $\mathrm{Hg}$ (II) and $\mathrm{Au}$ (III) in the determination of silver.

A $0.1 \mathrm{~mol} \mathrm{~L}^{-1}$ solution of sodium iodide was used to mask $\mathrm{Hg}$ (I, II) and $\mathrm{Ag}$ (I) in the determination of gold. The presence of hydroxylamine hydrochloride didn't affect the spectral characteristics of the $\mathrm{Au}-\mathrm{SR}$ ternary complex indicating that $\mathrm{Au}(\mathrm{III})$ has been already reduced to $\mathrm{Au}(\mathrm{I})$. However; the presence of ascorbic acid severely suppressed the absorbance of the complex denoting the reduction of $\mathrm{Au}(\mathrm{III})$ to the metallic gold. This finding replenishes the findings of Cotton and Woolf, ${ }^{30}$ and Borissova. ${ }^{53}$ Traces of an oxidizing agent such as hydrogen peroxide altered the spectral characteristics of the complex consolidating the previous findings.

Thus, in the implemented methods most interfering species were tolerated at three orders of magnitude compared to silver and gold. Moreover, a 100-fold excess of $\mathrm{Hg}$ (II), $\mathrm{Pt}(\mathrm{II})$, and $\mathrm{Au}$ (III) did not interfere in the determination of $\mathrm{Ag}$ (I). In addition, a 200fold excess of $\mathrm{Ag}(\mathrm{I})$, and $\mathrm{Hg}$ (II) and 150-fold excess of Pt(II), and $\mathrm{Pd}(\mathrm{II})$ did not interfere in the determination of $\mathrm{Au}(\mathrm{III})$; showing the extraordinary selectivity of the implemented methods.

\subsection{Applications}

The proposed method was conveniently applied to the assessment of silver in a pharmaceutical sample, gold in electroplating wastewater, and both silver and gold in rock samples. The pharmaceutical silver sulfadiazine burn cream under trade name Dermazin ${ }^{\mathrm{TM}}$; manufactured by Medical Union Pharmaceuticals (Abu-Sultan, Ismailia, Egypt) under license from Sandoz $\mathrm{GmbH}$ (Austria) was used. Electroplating wastewater was collected from Asfour Crystal (Shoubra El-khema, Cairo, Egypt). The geological samples were collected from some goldmines in Umm Qurayyat and Haimour (Wadi Allaqi, Aswan Governate), mongul, fatiri and Abu Marawat (Safaga-Qena Road, Red Sea Governate), and Um Atoud (Marsa Alam, Red Sea Governate). The analytical data obtained by the proposed method was validated by comparison with the corresponding spectrophotometric and the standard ICP-AES data.

The result obtained for silver in the pharmaceutical sample, as determined by the proposed procedure for seven replicates, was $0.987 \pm 0.019$ whereas the corresponding values obtained using ICP-AE spectrometry was $1.010 \pm 0.004$. For the determination of gold in two samples of electroplating wastewater, the results obtained were $1.285 \pm 0.011$ and $0.546 \pm 0.003$ and the corresponding values obtained with the ICP-AES were 1.271 \pm 0.007 and $0.529 \pm 0.001$ for seven replicates each. The results of silver and gold determination in the goldmines samples obtained using the proposed DIBA and spectrophotometric methods along with those of the ICP-AES method are summarized in Table 2 .
The statistical $t$-test and $F$-test at 95\% confidence level clearly show that there is no statistical difference between the means and variances of the proposed methods and the standard ICPAES methods.

\section{Conclusion}

This work proves the ability of scanner image analysis as an efficient competitor to conventional spectrophotometers for the optimization, validation, and application to the assessment of trace amounts of silver and gold in complex real samples using a novel and specifically tailored rhodanine derivative.

A comparison between the analytical characteristics of the proposed method, some of the well-established reagents for silver and gold, and some of the well-known rhodanine derivatives is clarified in Table 3. This work introduces competitive selectivity and precision and even greater simplicity, affordability and sensitivity compared to most of the previously reported spectrophotometric methods.

\section{Conflicts of interest}

There are no conflicts to declare.

\section{Notes and references}

1 R. Aznar, F. Barahona, O. Geiss, J. Ponti, T. Jose Luis and J. Barrero-Moreno, Talanta, 2017, 175, 200-208.

2 D. Tao, W. Guo, W. Xie, L. Jin, Q. Guo and S. Hu, Microchem. J., 2017, 135, 221-225.

3 Y. H. Liu, B. Wan and D. S. Xue, Molecules, 2019, 24, 3840.

4 S. Kilic, Environ. Monit. Assess., 2019, $191,452$.

5 P. Anekthirakun and A. Imyim, Microchem. J., 2019, 145, 470475.

6 M. M. Rahman, S. B. Khan, H. M. Marwani, A. M. Asiri, K. A. Alamry and A. O. Al-Youbi, Talanta, 2013, 104, 75-82.

7 J. Mizera, Z. Řanda and J. Kučera, J. Radioanal. Nucl. Chem., 2008, 278, 599-602.

8 A. El-Taher, K. L. Kratz, A. Nossair and A. H. Azzam, Radiat. Phys. Chem., 2003, 68, 751-755.

9 M. Ghosh, K. K. Swain, T. A. Chavan, D. N. Wagh and R. Verma, X-Ray Spectrom., 2015, 44, 13-15.

10 M. Amjadi, A. Samadi, J. L. Manzoori and N. Arsalani, Anal. Methods, 2015, 7, 5847-5853.

11 S. L. Ramesh, P. V. Sunder Raju, K. V. Anjaiah, R. Mathur, T. Gnaneswara Rao, B. Dasaram, S. N. Charan, D. V. Subba Rao, D. S. Sarma, R. Mekala and V. Balaram, At. Spectrosc., 2001, 22, 263.

12 X. Tang, H. Li, H. Liu, B. Li, Y. Zhao, J. Lu, J. Zhou and Q. Liu, J. Anal. Methods Chem., 2019, 2019, 1792792.

13 F. Salimi and M. Ramezani, Sep. Sci. Technol., 2019, 54, 2274-2282.

14 T. G. Choleva, G. Z. Tsogas and D. L. Giokas, Talanta, 2019, 196, 255-261.

15 G. K. Schweitzer and F. F. Dyer, Anal. Chim. Acta, 1960, 22, 172-180. 
16 S. Barua, B. S. Garg, R. P. Singh and I. Singh, Analyst, 1980, 105.

17 K. L. Cheng, Mikrochim. Acta, 1967, 55, 820-827.

18 M. Muraoka, T. Yamamoto and T. Takeshima, Analyst, 1979, 104, 87-90.

19 Y. S. Varma, I. Singh, B. S. Garg and R. P. Singh, Microchem. J., 1984, 29, 326-332.

20 A. W. Titley, Analyst, 1962, 87, 349-355.

21 S. G. Nagarkar and M. C. Eshwar, Anal. Chim. Acta, 1974, 71, 461-463.

22 B. Subrahmanyam and M. C. Eshwar, Anal. Chim. Acta, 1976, 82, 435-437.

23 H. S. Gowda, K. A. Padmaji and K. N. Thimmaiah, Analyst, 1981, 106, 198-205.

24 I. Singh, P. S. Kadyan, B. S. Garg and S. Barua, Bull. Chem. Soc. Jpn., 1989, 62, 1316-1320.

25 A. V. Dolgorev and Y. G. Lysak, Dithiopyrylmethane and its analogs as analytical reagents. Study of complex formation between dithiodiantipyrylmethane and gold, bismuth, and molybdenum, 1974.

26 R. Borissova, Talanta, 1975, 22, 797-802.

27 Y. Tanaka, Y. Saito, J. Odo and H. Omori, Bunseki Kagaku, 1980, 29, 381-384.

28 R. E. Godoy and A. G. Pérez, Analyst, 1986, 111, 1297-1299.

29 F. M. El-Zawawy, M. F. El-Shahat, A. A. Mohamed and M. T. M. Zaki, Analyst, 1995, 120, 549-554.

30 T. M. Cotton and A. A. Woolf, Anal. Chim. Acta, 1960, 22, 192194.

31 I. E. Lichtenstein, Anal. Chem., 2002, 47, 465-468.

32 G. G. Alfonso and J. L. G. Ariza, Microchem. J., 1981, 26, 574585.

33 K. Ohshita, H. Wada and G. Nakasawa, Anal. Chim. Acta, 1986, 182, 157-162.

34 M. C. Alvarez-Coque, R. M. Camanas, M. C. Vaya, G. R. Ramos and C. M. Fernandez, Talanta, 1986, 33, 697699.

35 A. A. Mohamed, A. A. Shalaby and A. M. Salem, RSC Adv., 2018, 8, 10673-10679.
36 A. A. Mohamed and A. A. Shalaby, Food Chem., 2019, 274, 360-367.

37 H. Kudo, K. Yamada, D. Watanabe, K. Suzuki and D. Citterio, Micromachines, 2017, 8, 127.

38 P. Masawat, A. Harfield, N. Srihirun and A. Namwong, Anal. Lett., 2016, 50, 173-185.

39 S. K. Vashist, T. van Oordt, E. M. Schneider, R. Zengerle, F. von Stetten and J. H. Luong, Biosens. Bioelectron., 2015, 67, 248-255.

40 C. L. M. Morais, K. M. G. Lima and F. L. Martin, Anal. Lett., 2019, 52, 2239-2250.

41 X. X. Zhang, Y. Z. Song, F. Fang and Z. Y. Wu, Anal. Bioanal. Chem., 2018, 410, 2665-2669.

42 M. Jafari, J. Tashkhourian and G. Absalan, Talanta, 2018, 178, 870-878.

43 C. d. L. Medeiros de Morais and K. M. G. de Lima, Talanta, 2014, 126, 145-150.

44 C. d. L. M. de Morais, S. R. B. Silva, D. S. Vieira and K. M. G. Lima, J. Chem. Educ., 2016, 93, 1760-1765.

45 J. A. V. A. Barros, F. M. d. Oliveira, G. d. O. Santos, C. Wisniewski and P. O. Luccas, Anal. Lett., 2016, 50, 414430.

46 D. C. Christodouleas, A. Nemiroski, A. A. Kumar and G. M. Whitesides, Anal. Chem., 2015, 87, 9170-9178.

47 P. L. Julian and B. M. Sturgis, J. Am. Chem. Soc., 1935, 57, 1126-1128.

48 E. W. Gorecki and J. M. Pepper, Can. J. Chem., 1959, 37, 2089-2092.

49 P. G. Jeffery and D. Hutchison, Chemical methods of rock analysis, Pergamon Press, New York, 3rd edn, 1981.

50 https://multid.se/datan/https://multid.se/datan/, accessed 23-7-2019, 2019.

51 M. J. Rosen and J. T. Kunjappu, Surfactants and interfacial phenomena, Wiley, 4th edn, 2012.

52 J. Inczédy, Analytical Applications of Complex Equilibria, Wiley, New York, 1976.

53 R. Borissova, Talanta, 1975, 22, 6. 